8 Guilleminault C, van den Hoed J, Mitler MM. Clinical overview of the sleep apnea syndromes. In: Guilleminault $\mathrm{C}$, Dement $\mathrm{W}$, eds. Sleep apnea syndromes. New York: Alan R Liss, 1978:1-12.

9 Lugaresi E, Coccagna G, Cirignotta F. Snoring and its clinical implications In: Guilleminault C, Dement W, eds. Sleep apnea syndromes. New York: Alan R Liss, 1978:13-21

10 Bloom JW, Kaltenborn WT, Quan SF. Risk factors in a general population for snoring. Importance of cigarette smoking and obesity. Chest 1988;93: $678-83$.

11 Guilleminault C, Eldridge FL, Simmons FB, Dement WC. Sleep apnea in eight children. Pediatrics 1976;58:23-30.

12 Guilleminault C, Winkle R, Korobkin R, Simmons B. Children and nocturnal snoring: evaluation of the effects of sleep related respiratory resistive load and davtime functioning. Eur 7 Pediatr 1982:139:165-71.

13 Mauer KW, Staats BA, Olsen KD. Upper airway obstruction and disordered nocturnal breathing in children. Mayo Clin Proc 1983;58:349-53.

14 Westbrook PR. The chronically snoring child: an acoustic annoyance or cause for concern? Mayo Clin Proc 1983;58:399.

15 Ferris BG. Epidemiology standardization project: children's questionnaire. Am Rev Respir Dis 1978;118(suppl):36-53.

16 Snedecor GW, Cochran WG. Statistical methods. 7th ed. Iowa: Iowa State University Press, 1980:215-33.

17 Mantel N. Chi-square test with one degree of freedom: extension of the Mantel-Haenszel procedure. Fournal of the American Statistical Association 1963;58:690-700

18 Cornfield J. A statistical problem arising from retrospective studies. In: Neyman J, ed. Proceedings of the third Berkeley symposium. Berkeley: University of California Press, 1956:133-48.

19 Mantel N, Haenszel W. Statistical aspects of the analysis of data from retrospectve studies of disease. Fournal of the National Cancer Institute $1959 ; 22: 719-48$

20 Robins J, Greenland S, Breslow NE. A general estimator for the variance of the Mantel-Haenszel odds ratio. Am $\mathcal{F}$ Epidemiol 1986;124:719-23.

21 Bradley TD, Brown IG, Grossman RF, et al. Pharyngeal size in snorers, nonsnorers, and patients with obstructive sleep apnea. $N$ Engl $\mathcal{Y ~ M e d ~}$ $1986 ; 315: 1327-31$

22 Sandblom RE, Matsumoto AM, Schoene RB, et al. Obstructive sleep apnea syndrome induced by testosterone administration. N Engl f Med 1983;308 508-10

23 Sutton FD, Zwillich CW, Creagh CE, Pierson DJ, Weil JV. Progesterone for outpatient treatment of Pickwickian syndrome. Ann Intern Med 1975;83 476-9.

24 Weil JV, Cherniak NS, Dempsey JA, et al. Respiratory disorders of sleep. Pathophysiology, clinical implications, and therapeutic approaches. Am Rev Respir Dis 1987;136:755-61.

25 Robin IG. Snoring Proceedings of the Royal Society 1968:61:575-82.

26 Hoffstein V, Chaban R, Cole P, Rubistein I. Snoring and upper airway properties. Chest 1988;94:87-9.
pofstein

27 McNicholas WT, Tarlo S, Cole P, et al. Obstructive apneas during sleep in patients with seasonal allergic rhinitis. Am Rev Respir Dis 1982;126:625-8.

28 Zwillich CW, Pickett C, Hanson FN, Weil JV. Disturbed sleep and prolonged apnea during nasal obstruction in normal men. Am Rev Respir Dis 1981;124:158-60.

29 Said G, Zalokar J, Lellouch J, Patois E. Parental smoking related to adenoidectomy and tonsillectomy in children. $f$ Epidemiol Commun Health 1978;32:97-101.

(Accepted 17 October 1989

\title{
Consequences and treatment of ovarian failure after total body irradiation for leukaemia
}

\author{
M P Cust, M I Whitehead, R Powles, Myra Hunter, S Milliken
}

\begin{abstract}
Objective-To assess the incidence and severity of physical and psychosexual symptoms in young women due to ovarian failure caused by total body irradiation for leukaemia and the women's response to hormone treatment.

Design-Postal questionnaire and interview.

Setting-Leukaemia unit of oncology hospital.

Patients-Consecutive series of 46 English speaking women who had developed ovarian failure after total body irradiation and bone marrow transplantation as treatment for leukaemia.

Results - Of the 36 responders, 33 reported some symptoms, vaginal dryness being the most common (29). This profoundly affected sexual function. Although 22 women had had sexual intercourse within six months after treatment, 16 were less interested in and 18 experienced difficulties with sexual intercourse. Anxieties about sterility, femininity, and appearance were common and reduced self confidence. Almost half reported that they had changed their social habits and restricted their social activities. Treatment seemed effective in abolishing symptoms in 24 women, but vaginal dryness remained a problem in three. Two women failed to respond and intercourse remained impossible.
\end{abstract}

Conclusions-Such patients are vulnerable and access to gynaecologists and endocrinologists soon after treatment would be valuable. The optimal treatment regimen and the long term benefits of treatment have yet to be established.

\section{Introduction}

Total body irradiation and bone marrow transplantation have recently become established treatments for certain types of leukaemia in younger patients. Because of the systemic nature of the disease, ' no attempt can be made to shield the gonads. Consequently, nearly all women develop amenorrhoea and permanent ovarian failure. As over half are likely to survive long term,,$^{23}$ recognition of the consequences of total body irradia- tion and premature ovarian failure are of great importance.

While there has been a recent expansion in our knowledge of the incidence and aetiology of all causes of premature ovarian failure ${ }^{4}$ little is known about the consequences. Various authors have commented on the presence of hot flushes, night sweats, and atrophy of the lower genital tract in patients with premature ovarian failure,${ }^{5.10}$ but some of these studies included patients who subsequently regained ovarian function spontaneously (and even became pregnant) and clearly, therefore, did not have irreversible ovarian failure. Furthermore, few previous studies have investigated the impact of oestrogen deficiency on sexual function and none on self esteem and social behaviour. We believe that such additional information is vitally important in clinically managing all patients with irreversible premature ovarian failure irrespective of aetiology.

We present data on some of the early consequences of ovarian failure and the effects of hormone therapy in a group of 36 women previously treated with total body irradiation and bone marrow transplantation for leukaemia.

\section{Patients and methods}

Forty six English speaking patients who had received total body irradiation and bone marrow transplantation at the leukaemia unit at the Royal Marsden Hospital were sent a questionnaire, to which 36 responded. All patients had received conditioning treatment with cyclophosphamide and total body irradiation or melphalan and total body irradiation. " The questionnaire referred to symptoms and concerns experienced by the patients in the six months after treatment.

Of those who responded to the questionnaire, 34 were referred to the unit from hospitals elsewhere in the United Kingdom (from as far afield as Cornwall in the south to the Orkney islands in the north); the two other patients were local. At the time of treatment the average age was $25 \cdot 7$ years (range 14.3 years to 42.6 years) and the mean time between treatment and 
questionnaire and interview was $4 \cdot 2$ years (range eight months to nine years). Eighteen of the 36 responders were single, 17 were married, and one was separated. Fourteen patients had been pregnant; 13 had had at least one child; and 22 patients were nulliparous. After treatment every patient remained amenorrhoeic until eventually started on hormone therapy.

The questionnaire obtained information on $(a)$ the frequency of classic oestrogen deficiency symptoms (flushes, sweats, and vaginal dryness); (b) patients' anxieties about sterility, appearance, and loss of menstruation and feelings about their femininity; $(c)$ the frequency and nature of sexual difficulties; $(d)$ change in social habits and difficulties with relationships; and $(e)$ what factors helped them cope with problems after treatment. Each section began with closed questions giving a choice of responses. For example, Please indicate (yes/no) those problems that you experienced in the six months after radiotherapy: (a) hot flushes. If yes, how often? Several times a day, a week, a month, a year. Open questions were also included to elicit the nature of other worries and anxieties. For example, Do you think your general appearance has changed since the operation? If yes, please say how. Questions were phrased in a positive and negative direction to avoid bias towards negative responses.

One of us (MIW) also interviewed most of the patients, and there was clear consistency between the results from the questionnaire and the interview. Data on the effects of hormone therapy on vasomotor symptoms and vaginal dryness were collected at interview and in the small number of patients not interviewed from the case records. At the time of the study we were unaware of the profound effects of premature ovarian failure on the psychological and psychosexual state, and information on the response of these symptoms to hormone treatment was therefore not collected.

\section{Results}

Table I shows the number of patients who had hot flushes, night sweats, and vaginal dryness, the number who reported each symptom to be a distressing problem, and the number who reported the frequency of hot flushes and night sweats. Vaginal dryness was the most commonly reported (29) and distressing (18) symptom. Only one of the 17 women married at the time of treatment did not report subsequent vaginal dryness. This symptom had a profound effect on sexual function. Three patients did not experience any of the above symptoms.

Table II gives data on anxieties about sterility, appearance, loss of menstruation, and loss of femin-

TABLE I - Numbers of patients who reported vasomotor and lower genital tract symptoms and frequency of occurrence after treatment for leukaemia

\begin{tabular}{lcccccc}
\hline & & & \multicolumn{4}{c}{ Frequency of symptom } \\
\cline { 4 - 7 } Symptom & $\begin{array}{c}\text { No who reported } \\
\text { symptom }\end{array}$ & $\begin{array}{c}\text { No in whom symptom } \\
\text { was a problem }\end{array}$ & Daily & Weekly & Monthly & Yearly \\
\hline Hot flushes & 22 & 6 & 7 & 8 & 3 & 4 \\
Night sweats & 13 & 5 & 1 & 5 & 4 & 3 \\
Vaginal dryness & 29 & 18 & & & & \\
\hline
\end{tabular}

TABLE II - Numbers of patients reporting various anxieties after treatment for leukaemia in relation to age and marital state

\begin{tabular}{lcccccccc}
\hline & & \multicolumn{3}{c}{ Age groups } & & \multicolumn{2}{c}{ Marital state } \\
\cline { 3 - 4 } Anxiety & $\begin{array}{c}\text { No who reported } \\
\text { problem }\end{array}$ & $\begin{array}{c}\leqslant 20 \\
(\mathbf{n}=11)\end{array}$ & $\begin{array}{c}21-29 \\
(\mathbf{n}=14)\end{array}$ & $\begin{array}{c}\geqslant 30 \\
(\mathbf{n}=11)\end{array}$ & & $\begin{array}{c}\text { Single } \\
(\mathbf{n}=18)\end{array}$ & $\begin{array}{c}\text { Married } \\
(\mathbf{n}=17)\end{array}$ \\
\hline Sterility & 12 & 7 & 3 & 2 & & 8 & 4 \\
Appearance & 17 & 4 & 6 & 7 & & 8 & 9 \\
Loss of menstruation & 5 & 2 & 2 & 1 & & 3 & 2 \\
Femininity & 14 & 4 & 5 & 5 & & 7 & 7
\end{tabular}

inity. The figures are broken down into three age bands ( $\leqslant 20$ years; $21-29$ years; and $\geqslant 30$ years) and by marital state, excluding the results from the one separated patient. Anxiety about sterility was more common in the younger patients (seven of 11 ) and in the unmarried patients (eight of 18). Only one of the 13 patients who had one or more children reported this concern compared with 11 of the 22 nulliparous patients. More patients aged $\geqslant 30$ were concerned about appearance (seven of 11) than were patients aged $\leqslant 20$ (four of 11 ). Irrespective of age the most commonly reported feature adversely affecting appearance was dry skin and hair (six of 17). Five patients expressed concern about amenorrhoea: one patient reported that it reminded her that she was sterile and another patient was under the misconception that by not having a period she was at an increased risk of cancer. Fourteen patients reported anxieties about femininity: four thought that this was due to infertility; two attributed it to problems with intercourse; and two thought that it was due to a change in their body shape, in particular to a decrease in breast size. Five patients complained of weight loss and five of weight gain.

Twenty two patients had had sexual intercourse within six months after treatment (table III): 20 of these experienced vaginal dryness and 18 experienced considerable pain leading to difficulties with intercourse. Two of these patients subsequently developed severe vaginismus, which made intercourse impossible. Sixteen were less interested in intercourse, and 14 reported difficulty achieving orgasm.

TABLE III - Problems with sexual function among 22 patients who had had sexual intercourse within six months after treatment for leukaemia

\section{Problem} No of patients

Vaginal dryness

Difficulties with intercourse Decreased interest in intercours Difficulty achieving orgasm

Seventeen patients reported that they had changed their social habits and restricted their social activities; 15 had experienced difficulties with relationships. Various reasons for these problems were cited, including (in the youngest age group) difficulties in settling in at school after a six month absence and overprotective parents; and (in the older age group) problems in talking to their partner and family about difficulties with intercourse and sterility. Those without children stated that they avoided contact with those in their peer group who had young children. Five patients stated that they had lost self confidence.

Nineteen of the 36 patients sought medical help for the problems: 11 from the hospital, three from the family doctor, and five from both. In retrospect, 22 would have liked to discuss their problems with a counsellor and thought that the best time was immediately after treatment. They also thought, however, that help should have been made available as and when the problems arose. Of the 17 who did not seek help, 10 did not consider the symptoms troublesome enough, whereas seven were "so grateful to be alive" that they were reluctant to complain. Of the factors that most helped patients to cope with the consequences of treatment, most thought that family (28), friends (22), and a supportive partner (20) were of greatest help. Twenty two patients thought that their own confidence and strength were contributing factors.

Information about hormone therapy was available for 34 of the 36 patients. Two patients were transferred back to the referring hospital and no record was available of any subsequent hormone treatment. Hormone therapy was prescribed for 30 patients. Four 
patients declined treatment as they considered that the symptoms were "not a problem." Treatment was initiated by the haematologists and oncologists in the leukaemia unit for 18 patients, by gynaecologists for seven, by paediatric endocrinologists for three, and by general practitioners for two patients.

Of those taking hormone therapy, 27 had symptoms and three received treatment as prophylaxis. Fourteen patients were prescribed the combined oral contraceptive pill, 14 received oral hormone replacement therapy with continuous oestrogen and cyclical progestogen ( 12 days each cycle), and two were prescribed oestrogen vaginal cream. The mean time from total body irradiation to starting hormone therapy was 16 months (range 3-55 months). Treatment abolished hot flushes, night sweats, and vaginal dryness in 22 of the 27 patients with symptoms. In three patients their symptoms improved and in two there was no change. The residual symptoms in these five was vaginal dryness. This problem was eventually completely resolved in two patients by increasing the dose of oestrogen and changing to oral treatment. This strategy was only partially successful in a third patient and intercourse remained "less enjoyable"; it failed totally in two patients in whom intercourse had become impossible because severe vaginal dryness led to intense vaginismus. Despite normal anatomy, psychosexual counselling, and high dose oestrogens the vaginismus could not be overcome and intercourse remained impossible.

\section{Discussion}

We undertook this survey to provide data on the frequency and severity of various symptoms experienced by fairly young women with leukaemia who suffered ovarian failure due to total body irradiation. Certain symptoms, such as hot flushes, night sweats, and vaginal dryness, were due to lack of oestrogen, and only three patients did not experience any of these symptoms. While flushes and sweats were reported by 22 and 13 patients respectively they caused distress in only six. We were surprised not only by these low proportions but also by the much higher prevalence of vaginal dryness (29 patients), which was a significant problem in 18 patients.

Unlike in other reports we collected data on anxieties that resulted from ovarian failure. One third of all our patients were concerned about sterility, and, as expected, this was reported more often in the single patients (eight out of 18 ) and in those aged $\leqslant 20$ years (seven out of 11 ). Only two out of 11 patients aged $\geqslant 30$ years expressed this anxiety. Overall, only five patients were concerned by amenorrhoea, and one of these was under a misconception.

Feelings of loss of femininity were common and reported by about two fifths of patients. Interestingly, this figure was not age related and was similar in the three age groups and in the single and married women. In six of the 14 patients reporting this it was clearly related to oestrogen deficiency (infertility and difficult intercourse), and two others felt less feminine because of a reduction in breast size. Similar comments apply to the effects of treatment on appearance: almost half $(17)$ of the patients reported that their appearance had been adversely affected, with dry skin and dry hair the commonest cited reasons. Although naturally postmenopausal women in their early 50 s often complain of these changes and a protein associated to the oestradiol receptor has been identified in epidermis, hair follicles, and sebaceous glands (which suggest that these tissues are oestrogen dependent), ${ }^{12}$ this problem might also arise in part from the effects of generalised radiation and graft versus host disease and its treatment. ${ }^{1314}$

Although numbers were too small for meaningful statistical analysis, the reports of anxiety about appearance increased with age (four of 11 at $\leqslant 20$ years and seven of 11 at $\geqslant 30$ years) and were more common in married (nine) than single (eight) women. Serial weight measurements were not available, but the effects of total body irradiation and ovarian failure on weight seem inconsistent: five patients reported distinct weight loss but five reported troublesome weight gain. The effects on sexual interest, enjoyment, and performance, however, are quite clear and devastating. Twenty two patients had had intercourse during the six months after treatment: 20 reported vaginal dryness, 18 experienced pain or difficulties, 16 reported decreased interest, and 14 experienced difficulties in achieving orgasm. Appropriate oestrogen doses cured these deficiency symptoms in 24 women with symptoms but in those with continuing problems, vaginal dryness rather than vasomotor symptoms persisted.

Vaginal dryness was eventually overcome in three of five patients with continuing dryness by increasing the dose of oestrogen. Two patients, however, who had developed vaginismus because of severe pain during intercourse soon found intercourse impossible despite normal anatomy, psychosexual therapy, and high doses of oestrogen. Clearly high doses must be prescribed before irreversible psychological damage occurs. For these reasons we doubt whether the reduction in sexual interest resulted from feelings of loss of femininity and anxiety about appearance. The anxiety, however, may well have contributed to changes in social habits and restrictions on social activities, problems that were common and were reported by 17 and 15 patients respectively.

As techniques for successfully treating leukaemia improve further and become even more widely implemented so more young women can be expected to survive. Because of ovarian failure their major long term risks are likely to include increased risks of osteoporosis (because bone mass is more dependent on ovarian state than age ${ }^{15}$ ) and arterial diseases. Premature surgical castration doubles the risk of certain arterial diseases ${ }^{16}$ and we see no reason why patients with premature ovarian failure due to radiation should behave differently. Hormone therapy should be considered virtually mandatory both for relief of the short term symptoms and for prophylaxis against the long term results. ${ }^{16}$

While some authors have recommended oestrogen and progestogen therapy for patients with premature ovarian failure ${ }^{10}{ }^{17}$ no data are available on the optimal regimen. Whether conventional hormone replacement therapy (natural oestrogen with sequential progestogen) confers any advantage over the combined oral contraceptive (synthetic oestrogen and progestogen) in this younger age group is unknown. Both natural and synthetic oestrogens prevent postmenopausal bone loss. ${ }^{119}$ Whether they behave similarly or differently with respect to arterial diseases, however, is unknown. Although differences exist in their effects on lipid and lipoprotein metabolism, ${ }^{2021}$ no long term epidemiological data on risk of arterial disease are available for valid comparisons.

Compliance is also an important issue. Our experience was that some patients had strong views on whether conventional hormone replacement therapy or the contraceptive pill was more acceptable. Younger patients preferred the pill because it passed without comment among their peer group. Conversely, older women were more prepared to accept conventional hormone replacement therapy. The early consequences of total body irradiation reported here must not be overlooked because they are common and because, collectively, sexual dysfunction, concerns about sterility and appearance, and restriction on social 
activities will reduce the quality of life and lower self confidence and self esteem. Patients with ovarian failure induced by radiation should be regarded as vulnerable and while access to a gynaecologist or endocrinologist, or both, early after treatment would be valuable (and might be considered mandatory), 22 of our patients thought in retrospect that they might have benefited from special counselling and that such help should have been available as and when the problems arose. We conclude that there is an urgent need for the establishment of such a multidisciplinary service that could then undertake a prospective study into these problems.

We thank Sarah Milan for her help with the data handling, the Imperial Cancer Research Fund Laboratories for financial help for MIW, and the Wynn Institute for financial help for MPC.

1 Gale RP, Champlin RE. Bone marrow transplantation in acute leukaemia. Clinics in Haematology 1986;15:851-72.

2 Clift RA, Buckner CD, Thomas ED, et al. The treatment of acute nonlymphoblastic leukaemia by allogeneic marrow transplantation. Bone Marrow Transplantation 1987;2:243-58.

3 Doney K, Buckner CD, Kopecky KJ, et al. Marrow transplantation for patients with acute lymphoblastic leukaemia in first marrow remission. Bone Marrow Transplantation 1987;2:355-63.

4 Coulam CB, ed. Seminars in reproductive endocrinology. Vol 1, No 2. New York: Thieme-Stratton, 1983:177-8.

5 Russell P, Bannatyne P, Shearman RP, Fraser IS, Corbett P. Premature hypergonadotropic ovarian failure: clinicopathological study of 19 hypergonadotropic ovarian failure: clinco
cases. Int f Gynecol Pathol 1982;1:185-201.

6 Board JA, Redwine FO, Moncure CW, Frable WJ, Taylor JR. Identification of differing etiologies of clinically diagnosed premature

7 Rebar RW, Erickson GF, Yen SSC. Idiopathic premature ovarian failure: clinical and endocrine characteristics. Fertil Steril 1982;37:35 41 .
8 Zarate A, Karchmer S, Gomez E, Castelazo-Ayala L. Premature menopause. A clinical, histologic and cytogenetic study. Am $\mathcal{J}$ Obste Gynecol 1970;106:110-4.

9 Keettel WC, Bradbury JT. Premature ovarian failure, permanent and temporary. Am f Obstet Gynecol 1964;89:83-96.

10 Aiman J, Smentek C. Premature ovarian failure. Obstet (ivnecol 1985;66:9-14.

11 Helenglass G, Powles RL, McElwain TG, et al. Melphalan and total body irradiation versus cyclophosphamide and total body irradiation as the conditioning for allogeneic matched sibling bone marrow transplantation for first remission acute myeloid leukaemia. Bone Marrow Transplant 1988:3:21-9.

12 Padwick ML, Whitehead MI, Coffer A, King RJB. Demonstration of oestrogen receptor related protein in female tissues. In: Studd JWW, Whitehead MI, eds. The menopause. London: Blackwell, 1988;227-33.

13 Sullivan KM, Shulman HM, Storb R, et al. Chronic graft-versus-hos disease in 52 patients: adverse natural course and successful treatmen with combination immunosuppression. Blood 1981;57:267-76.

14 Marin P, Granena A, Martin E, et al. Epidermal dysplasia an cyclosporin A in bone marrow transplant recipients. Bone Marrow Transplant 1986;1:84.

15 Richelson LS, Wahner HW, Melton LJ III, Riggs BL. Relative contributions of aging and estrogen deficiency to postmenopausa bone loss. N Engl f Med 1984;311:1273-5.

16 Colditz GA, Willett WC, Stampfer MJ, Rosner B, Speizer FE, Hennekens $\mathrm{CH}$. Menopause and the risk of coronary heart disease in women. $N$ Engl f Med 1987:316:1105-10.

17 Alper MM, Garner PR, Seibel MM. Premature ovarian failure. 7 Reprod Med 1986;31:699-708

18 Christiansen C, Christiansen GS, McNair P, Hagen C, Stocklund E, Transbol I. Prevention of early postmenopausal bone loss; controlled 2-year study in 315 normal females. Eur f Clin Invest 1980;10:273-79.

19 Lindsay R, Hart DM, Aitken JM, Macdonald EB, Anderson JB, Clark AC. Long-term prevention of postmenopausal osteoporosis by oestrogen. Lancet 1976; ; 1038-4

20 Farish E, Fletcher CD, Hart DM, Teo C, Alazzawi F, Howie C. The effects of conjugated equine oestrogens with and without a cyclical progestogen on lipoproteins, and HDL subfractions in postmenopausal women. Acta Endocrinol (Copenh) 1986;113:123-7.

21 Lipson A, Stoy B, LaRosa JC, et al. Progestins and oral contraceptiveinduced lipoprotein changes: a prospective study. Contraception 1986;34:121-34.

\section{Body weight and mortality in middle aged British men: impact of smoking}

Goya Wannamethee, A G Shaper

Abstract

Objective-To assess the relation between body mass index and mortality in middle aged British men.

Design-Men who were recruited for the British Regional Heart Study were followed up for a mean of nine years.

Setting-General practices in 24 British towns.

Subjects-7735 Men aged 40-59 years selected from the age-sex registers of one group practice in each of the 24 towns.

Main outcome measure-Mortality from cardiovascular and non-cardiovascular causes.

Results-660 Of the men died. There was a $U$-shaped relation between body mass index and total mortality. Very lean men $\left(<20 \mathrm{~kg} / \mathrm{m}^{2}\right)$ had by far the highest mortality followed by lean men $\left(20-22 \mathrm{~kg} / \mathrm{m}^{2}\right)$ and obese men $\left(\geqslant 28 \mathrm{~kg} / \mathrm{m}^{2}\right)$. The high mortality in lean and very lean men was due largely to non-cardiovascular causes, particularly lung cancer and respiratory disease, which are associated with cigarette smoking. In obese men deaths were more likely to be due to cardiovascular causes. There was a strong inverse association between body weight and cigarette smoking. When the pattern of mortality was examined by age, smoking habits, and preexisting smoking related disease both very lean men and obese men consistently had an increased mortality. The U-shaped relation was most prominent in men in the oldest age group (55-59). Current smokers had a higher mortality than former smokers at virtually all values of body mass index. An increased mortality in lean men was seen only in current smokers and in men with smoking related disease. Among men who had never smoked, lean men had the lowest total mortality, thereafter mortality increased with increasing body mass index $(\mathbf{p}<\mathbf{0 . 0 1})$.

Conclusions-This study provides strong evidence of the impact of cigarette smoking on body weight and mortality and strongly suggests that the benefits of giving up smoking are far greater than the problems associated with the increase in weight that may occur.

\section{Introduction}

It is widely accepted that being overweight is associated with an increased risk to health, in particular with regard to hypertension, diabetes mellitus, and ischaemic heart disease.' More recently, attention has been given to the problem of being underweight, and studies on body weight and mortality have produced conflicting results: some showed no relation, ${ }^{23}$ one reported a positive linear relation, ${ }^{4}$ and several have suggested a J-shaped or U-shaped relation..$^{5-12}$ The increased risk of death seen in lean people in the currently accepted desirable weight range and in obese people has raised the question of optimal or desirable weight associated with the lowest mortality. In a review of studies of body weight and mortality Manson et al suggested that the discrepancies in findings may be due to methodological biases associated with inadequate control for smoking, inappropriate control of physiological and metabolic effects of obesity, and 